\title{
Square-Wave Voltammetry of a Second Order Cathodic Stripping Process Coupled by Adsorption of the Reacting Ligand
}

\author{
Rubin Gulaboski*a, Valentin Mirčeski ${ }^{\mathrm{a}}$, and Šbojka Komorsky-Lovrićb \\ a Institute of Chemistry, Faculty of Natural Sciences and Mathematics, p.o. box 162, "Sts. Cyril and Methodius" University, Skopje, \\ Macedonia; e-mail: valentin@iunona.pmf.ukim.edu.mk; rubingulaboski@excite.com \\ b Center for Marine Research Zagreb, "Ruđer Bošković" Institute, p.o. box 1016 Zagreb 1001, Croatia
}

Received: April 11, 2001

Final version: June 7, 2001

\begin{abstract}
A new theory of a second order cathodic stripping reaction accompanied by adsorption of the reacting ligand is developed under conditions of square-wave voltammetry. In the mathematical model, the following reaction is considered:

$$
2 \mathrm{~L}^{-}(\mathrm{ads}) \Leftrightarrow 2 \mathrm{~L}^{-}(\mathrm{aq})+\mathrm{Hg}(\mathrm{l}) \Leftrightarrow \operatorname{HgL}_{2}(\mathrm{~s})+2 \mathrm{e}^{-}
$$

The relationships between the properties of the voltammetric response and both the kinetic parameters as well as the parameters of the excitement signal were analyzed. Both reversible and quasireversible redox reactions were examined. Criterions for distinguishing the studied mechanism from the other types of cathodic stripping reactions were established. The phenomenon of a quasireversible maximum was studied in details. The theoretical results are qualitatively compared with the SW voltammograms of 6-propyl-2-thiouracil.
\end{abstract}

Keywords: Square-wave voltammetry, Adsorption, Mechanistic studies, Cathodic stripping reaction, 6-Propyl-2thiouracil

\section{Introduction}

Cathodic stripping voltammetry is a well-known electroanalytical method for determination of various species capable to create sparingly soluble compounds with mercury or silver ions [1 -6]. In the course of the deposition step, the working electrode is polarized anodically at a constant potential. Consequently, a film of insoluble compound formed during the deposition step covers the working electrode surface. During the subsequent stripping step, the deposited film is stripped off from the electrode surface by cathodic polarization of the electrode.

Among the numerous factors affecting the overall method, its sensitivity depends considerably on the voltammetric technique employed in the stripping step. Most frequently, square-wave voltammetry is a technique of choice [7]. This technique possesses unique advantages, since it provides an insight view into the mechanism of the electrode process and enables kinetic characterization of the redox process and moreover, it exhibits the highest sensitivity to the reacting compound [4-17].

If mercury was used as a working electrode, a general reaction scheme describing the cathodic stripping process in a case of a divalent ligand reads:

$\operatorname{Hg}(\mathrm{l})+\mathrm{L}^{2-}(\mathrm{aq}) \Leftrightarrow \operatorname{HgL}(\mathrm{s})+2 \mathrm{e}^{-}$

The theoretical consideration of this important class of redox processes under conditions of SWV was initiated by Lovrić et al. [12]. These authors stressed that the voltammetric properties of the Reaction I are rather similar with the redox reaction of an adsorbed reactant $[16,17]$, although the nature of these two redox processes is intrinsically different. Recently, Mirčeski and Lovrić [13] confirmed that the cathodic stripping reaction (I) exhibits the phenomenon of "quasireversible maximum" which appears to be an inherent property of the whole class of redox reactions of an immobilized reactant regardless the way in which the immobilization is achieved. Moreover, it was emphasized that Reaction I could be characterized equally either by a standard rate constant $k_{\mathrm{s}}\left(\mathrm{cm} \mathrm{s}^{-1}\right)$ or $k_{\mathrm{s}}\left(\mathrm{s}^{-1}\right)$, ranking this reaction as an intermediate electrode mechanism between the diffusion controlled processes and the surface processes of an immobilized redox couple [13].

The scientific interest for the theoretical examination of the cathodic stripping processes has significantly raised in the recent years [4,5,12-15]. Thus, we have recently studied theoretically the cathodic stripping process of second order (Reaction II) [14] as well as the cathodic stripping reaction of first order coupled by adsorption of the reacting ligand (Reaction III) [4].

$$
\begin{aligned}
& \mathrm{Hg}(\mathrm{l})+2 \mathrm{~L}^{-}(\mathrm{aq}) \Leftrightarrow \operatorname{HgL}_{2}(\mathrm{~s})+2 \mathrm{e}^{-} \\
& \mathrm{L}^{2-}(\mathrm{ads}) \Leftrightarrow \mathrm{L}^{2-}(\mathrm{aq})+\mathrm{Hg}(\mathrm{l}) \Leftrightarrow \mathrm{HgL}(\mathrm{s})+2 \mathrm{e}^{-}
\end{aligned}
$$

In the present article we are extending our theoretical consideration to the complex cathodic stripping electrode mechanism of second order coupled by adsorption of the reacting ligand (Reaction IV).

$$
2 \mathrm{~L}^{-}(\mathrm{ads}) \Leftrightarrow 2 \mathrm{~L}^{-}(\mathrm{aq})+\mathrm{Hg}(\mathrm{l}) \Leftrightarrow \operatorname{HgL}_{2}(\mathrm{~s})+2 \mathrm{e}^{-}
$$


This is a complex second-order electrode mechanism involving the phenomenon of deposited insoluble compound on the electrode surface, as well as the adsorption of an electrochemically inactive compound capable to react with the working electrode material. This mechanism is of particular interest, since many organic compounds reacting as monovalent ligands are capable to adsorb on the electrode surface $[3,14]$.

The aim of this work is to investigate the relationships between the properties of the SW voltammetric response and both the redox kinetic parameters and parameters of the excitation signal. The results obtained theoretically are compared qualitatively with the SW cathodic stripping voltammograms of 6-propyl-2-thiouracil (PTU).

The voltammetric properties of the redox reaction of mercury in the presence of PTU are well known [4]. In our previous publication, this compound was used to illustrate the theory of the first order cathodic stripping process accompanied by an adsorption of the reacting ligand (Reaction III) [4]. However, the latest experimental results presented in this paper fit better to the second order cathodic stripping process.

As an uracil derivative, PTU is a cathodic stripping active due to its ability to react chemically with mercury, yielding a corresponding sparingly soluble salt [18]. On the other hand, Wandlowski and co-workers [19-21] studied the adsorption of PTU on the mercury/electrolyte interface. It was demonstrated that this compound could be strongly adsorbed on the electrode surface with pronounced interactions between PTU molecules and the mercury surface [21]. Consequently, a condensed film of strongly adsorbed PTU molecules on the mercury surface is formed. Under positive charge densities, in addition to the chemisorption of PTU, the onset of faradic processes, possibly involving the oxidative formation of mercury-compounds, have been observed [21].

\section{Mathematical Model}

In the mathematical treatment of Reaction IV a linear relationship between the surface concentration of the ligand and its concentration at the electrode surface is presumed. It is also presumed that there are no significant interactions between the deposited particles of $\mathrm{HgL}_{2}$ and $\mathrm{L}^{-}$forms. Therefore, the adsorption of $\mathrm{L}^{-}$could be described by a linear adsorption isotherm: $c(\mathrm{~L})_{x=0}=K_{\text {ads }} \cdot \Gamma(\mathrm{L})$, where $K_{\text {ads }}$ $\left(\mathrm{cm}^{-1}\right)$ is adsorption constant. In the electrode mechanism (IV) the following redox reactions could be considered:

$\mathrm{HgL}_{2}(\mathrm{~s})+2 \mathrm{e}^{-} \Leftrightarrow \mathrm{Hg}(\mathrm{l})+2 \mathrm{~L}^{-}(\mathrm{aq})$

$\mathrm{HgL}_{2}(\mathrm{~s})+2 \mathrm{e}^{-} \Leftrightarrow \mathrm{Hg}(\mathrm{l})+2 \mathrm{~L}^{-}(\mathrm{ads})$

In the conditions of equilibrium, Nernst's equation for Reaction 1 reads:

$E=E_{1}^{0}+\frac{R T}{2 F} \cdot \ln \frac{\Gamma\left(\mathrm{HgL}_{2}\right) \cdot c_{\mathrm{s}}^{2}}{c^{2}(\mathrm{~L}) \cdot \Gamma_{\mathrm{s}}}$, where $E_{1}^{0}=E_{\mathrm{Hg}^{2+/ \mathrm{Hg}}}^{0}+\frac{R T}{2 F} \ln K_{1}$. Here, $E_{\mathrm{Hg}^{2+/ \mathrm{Hg}}}^{0}$ is a standard redox potential of the reaction $\operatorname{Hg}^{2+}(\mathrm{aq})+2 \mathrm{e}^{-}$ $\rightleftarrows \mathrm{Hg}(\mathrm{l})$, and $K_{1}$ is the equilibrium constant of the following reaction: $\mathrm{HgL}_{2}(\mathrm{~s}) \leftrightharpoons \mathrm{Hg}^{2+}(\mathrm{aq})+2 \mathrm{~L}^{-}(\mathrm{aq})$ defined as, $K_{1}=\frac{r_{\mathrm{s}}}{c_{\mathrm{s}}^{2}} \cdot \frac{c\left(\mathrm{Hg}^{2+}\right)_{\mathrm{x}=0} \cdot c^{2}(\mathrm{~L})_{\mathrm{x}=0}}{\Gamma\left(\mathrm{HgL}_{2}\right)}, \quad$ where $\quad c_{\mathrm{s}}=1 \mathrm{~mol} / \mathrm{cm}^{3}$ and $\Gamma_{\mathrm{s}}=1 \mathrm{~mol} / \mathrm{cm}^{2}$ are the standard concentrations and $r_{\mathrm{s}}$ is an auxiliary constant with unit $\mathrm{cm}$, defined as $r_{\mathrm{s}}=\frac{\Gamma_{\mathrm{s}}}{c_{\mathrm{s}}}$. The mining of all the other symbols and abbrevations are given in Section 5.

Nernst's equation for the equation 2 reads:

$E=E_{2}^{0}+\frac{R \cdot T}{2 \cdot F} \cdot \ln \frac{\Gamma\left(\mathrm{HgL}_{2}\right) \cdot \Gamma_{\mathrm{s}}}{\Gamma^{2}(\mathrm{~L})}$,

where $E_{2}^{0}=E_{\mathrm{Hg}^{2+/ H g}}^{0}+\frac{R \cdot T}{2 \cdot F} \ln K_{2}$ and $K_{2}$ is a constant of the following reaction: $\mathrm{HgL}_{2}(\mathrm{~s}) \Leftrightarrow \mathrm{Hg}^{2+}(\mathrm{aq})+2 \mathrm{~L}^{-}(\mathrm{ads})$, defined as $K_{2}=\frac{c\left(\mathrm{Hg}^{2+}\right)_{\mathrm{x}=0} \cdot \Gamma_{\left(\mathrm{L}^{-}\right)}^{2}}{\Gamma_{\left(\mathrm{HgL}_{2}\right)} \cdot c_{\mathrm{s}} \cdot \Gamma_{\mathrm{s}}}$.

The equilibrium constants $K_{1}$ and $K_{2}$ are related through the adsorption constant according to the following equation: $K_{1} / K_{2}=K_{\text {ads }}^{2} \cdot r_{\mathrm{s}}^{2}$. An analogous interdependence exists between the standard redox potentials $E_{1}{ }^{0}$ and $E_{2}{ }^{0}$ of Reactions 1 and 2:

$E_{1}^{0}=E_{2}^{0}+R T / F \ln K_{1} / K_{2}$.

The mass transport of the reacting ligand towards the electrode surface could be described by a semi infinite stationary planar diffusion, which is represented by the following equation:

$\frac{\partial c(\mathrm{~L})}{\partial t}=D \cdot \frac{\partial^{2} c(\mathrm{~L})}{\partial x^{2}}$

The latest differential equation is solved by Laplace transformations under following initial and boundary conditions:

$$
\begin{aligned}
& t=0, x \geq 0, c(\mathrm{~L})=c(\mathrm{~L})^{*}, \Gamma\left(\mathrm{HgL}_{2}\right)=\Gamma(\mathrm{L})=0 \\
& t>0, x \rightarrow \infty, c(\mathrm{~L}) \rightarrow c(\mathrm{~L})^{*} \\
& x=0: \quad D \cdot\left(\frac{\partial c(\mathrm{~L})}{\partial x}\right)_{\mathrm{x}=0}-\frac{\partial \Gamma(\mathrm{L})}{\partial t}=2 \cdot \frac{\mathrm{d} \Gamma\left(\mathrm{HgL}_{2}\right)}{\mathrm{d} t} \\
& D \cdot\left(\frac{\partial c(\mathrm{~L})}{\partial x}\right)_{\mathrm{x}=0}-\frac{\partial \Gamma(\mathrm{L})}{\partial t}=-\frac{I}{2 F S} \\
& \frac{\mathrm{d} \Gamma\left(\mathrm{HgL}_{2}\right)}{\mathrm{d} t}=-\frac{1}{2} \cdot \frac{I}{2 F S} \\
& c(\mathrm{~L})_{x=0}=K_{\mathrm{ads}} \cdot \Gamma(\mathrm{L})
\end{aligned}
$$

The solutions for $\Gamma\left(\mathrm{HgL}_{2}\right)$ and $c(\mathrm{~L})_{x=0}$ are given with the following equations: 


$$
\begin{aligned}
& \Gamma\left(\mathrm{HgL}_{2}\right)=-\frac{1}{2} \int_{0}^{t} \frac{I(\tau)}{2 F S} \cdot \mathrm{d} \tau \\
& c(\mathrm{~L})_{x=0}=c(L)^{*} \cdot\left[1-\exp \left(a^{2} \cdot t\right) \cdot \operatorname{erfc}(a \cdot \sqrt{t})\right] \\
&+a \cdot \int_{0}^{t} \frac{I(\tau)}{2 F S \sqrt{D}} \cdot \exp \left(a^{2} \cdot(t-\tau)\right) \\
& \cdot \operatorname{erfc}(a \cdot \sqrt{t-\tau}) \cdot \mathrm{d} \tau
\end{aligned}
$$

where, $a=K_{\mathrm{ads}} \cdot D^{1 / 2}$, and $c(\mathrm{~L}) *$ is the concentration of the ligand in the bulk of the solution. If the electrode mechanism is reversible, Equations 4 and 5 are substituted in the Nernst's equation (3), and the following integral equation is obtained:

$$
\begin{aligned}
&-\frac{1}{2 r_{\mathrm{s}}} \cdot \int_{0}^{t} \frac{\mathrm{I}(\tau)}{2 F S} \cdot \mathrm{d} \tau=\frac{1}{c_{\mathrm{s}}} \cdot {\left[c(\mathrm{~L})^{*}\right.} \\
& \cdot {\left[1-\exp \left(a^{2} \cdot t\right) \cdot \operatorname{erfc}(a \cdot \sqrt{t})\right]+} \\
& a \cdot \int_{0}^{t} \frac{I(\tau)}{2 F S \sqrt{D}} \cdot \exp \left(a^{2} \cdot(t-\tau)\right) \\
&\cdot \operatorname{erfc}(a \sqrt{t-\tau}) \cdot \mathrm{d} \tau]^{2} \cdot \exp (\varphi)
\end{aligned}
$$

where $\varphi=\frac{2 \cdot F}{R \cdot T} \cdot\left(E-E_{1}^{0}\right)$ is a dimensionless potential.

If the mechanism IV is controlled kinetically, the following condition is valid:

$\frac{I}{2 F S}=k_{\mathrm{s}} \cdot \exp (-\alpha \cdot \varphi) \cdot\left(\frac{\Gamma\left(\mathrm{HgL}_{2}\right)}{r_{\mathrm{s}}}-\frac{c^{2}(\mathrm{~L})_{\mathrm{x}=0}}{c_{\mathrm{s}}} \cdot \exp (\varphi)\right)$

where $k_{\mathrm{s}}$ is the standard rate constant $\left(\mathrm{cm} \mathrm{s}^{-1}\right)$. Substituting Equations 6 and 7 into the kinetic equation (9), one obtains the integral equation (10)

$$
\begin{aligned}
\frac{I}{2 F S}=k_{\mathrm{s}} & \cdot \exp (-\alpha \cdot \varphi) \cdot\left[\frac{-1}{2 r_{\mathrm{s}}} \cdot \int_{0}^{t} \frac{I(\tau)}{2 F S} \cdot \mathrm{d} \tau\right. \\
- & \frac{\exp (\varphi)}{c_{\mathrm{s}}}\left(c_{(\mathrm{L})} * \cdot\left[1-\exp \left(a^{2} \cdot t\right) \cdot \operatorname{erfc} \cdot(a \cdot \sqrt{t})\right]\right. \\
+ & a \cdot \int_{0}^{t} \frac{I(\tau)}{2 F S \sqrt{D}} \cdot \exp \left(a^{2}\right. \\
& \left.\cdot(t-\tau)) \cdot \operatorname{erfc}(a \cdot \sqrt{t-\tau}) \cdot \mathrm{d} \tau)^{2}\right]
\end{aligned}
$$

The integral equations ( 8 and 10) may be regarded as a general mathematical representation of the reversible and quasireversible reaction of the mechanism (IV) under voltammetric conditions. They are valid for any chronoamperometric technique.

The latest equations were numerically solved under conditions of square-wave voltammetry according to the previously described method by Nischolson and Olmstead [22]. Both variables, current $I$ and time $t$, were incremented. To each time $t=m d$, where $d$ is a time increment, a certain current $I_{m}$ was ascribed. For $1 \leq m \leq M_{1}$ (where $M_{1}=t_{\text {acc. }} d$ and $t_{\text {acc. }}$ is the accumulation time) the electrode is polarized at a constant accumulation potential $E_{\text {acc. }}$. For numerical simulation a time increment $d=1 /(50 f)$ was used. It means that each SW half-period $\tau / 2$ was divided into 25 increments. In the period $M_{1} \leq m \leq M\left(M=t_{1} d\right.$ where $t_{1}$ is the total time calculated as a sum of accumulation time and time of the stripping scan) a square-wave potential excitation signal was applied at the working electrode. Square-wave potential signal is a train of a cathodic and anodic pulses superposed to a staircase potential ramp. The signal is characterized with amplitude $E_{s w}$, which is a half of the peak to peak height, a frequency of the pulses $f$ and a step of the staircase potential $\operatorname{ramp} \mathrm{d} E$.

The dimensionless current is represented in the form $\Psi=\frac{I}{2 F S \sqrt{D f} c(\mathrm{~L})^{*}}$

\section{Experimental}

All chemicals used were of analytical reagent grade. PTU is a product of Henkel KG\&A Co. (Germany) whereas, $\mathrm{KNO}_{3}$, methanol, and acetonitrile were from Merck. Redistilled water was used. $1 \mathrm{~mol} \mathrm{dm}^{-3} \mathrm{KNO}_{3}$ solution was used as a supporting electrolyte. The stock solution of PTU was prepared by dissolving in an appropriate amount of methanol. Extra pure nitrogen was used for purging the electrolyte solutions for $8 \mathrm{~min}$ prior to each measurement. A nitrogen blanket, over the electrolyte solution, was maintained thereafter.

All voltammograms were recorded using an Autolab multimode polarograph (ECO Chemie, Utrecht, Netherlands) which was connected to a PC Pentium 2 and a Model 303 A static mercury drop electrode (SMDE) from Princeton Applied Research. A platinum wire was used as an auxiliary electrode and $\mathrm{Ag} / \mathrm{AgCl}(3 \mathrm{~mol} / \mathrm{L} \mathrm{KCl})$ was the reference. All measurements were carried out at room temperature. Three consecutive voltammetric measurements were performed for each condition and mean values were presented.

\section{Theoretical Results}

\subsection{Reversible Redox Reaction}

Numerically simulated SW voltammograms are bell-shaped current-potential curves characterized by dimensionless peak current $\Delta \Psi_{\mathrm{p}}$, peak potential $E_{\mathrm{p}}$, and half-peak width $\Delta E_{\mathrm{p} / 2}$. These properties of the voltammetric response are determined mainly by time and the potential applied during the accumulation step, adsorption strength and the concentration of the reacting ligand, as well as the parameters of the excitement SW signal.

The amount of the insoluble salt initially precipitated on the working electrode surface depends predominantly on 
the accumulation time $t_{\text {acc }}$ and accumulation potential $E_{\text {acc }}$ adjusted in the course of the deposition step and hence, these parameters affect mainly the height of the SWV response. The dimensionless peak current depends sigmoidally on the accumulation potential. As can be seen from Figure 1, the beneath and the upper plateau of the pseudopolarogram are formed for $E_{\text {acc }}-E^{0}<0.1$ and $E_{\text {acc }}$ $-E^{0}>0.25 \mathrm{~V}$, respectively. Within the interval $0.1<E_{\text {acc }}-$ $E^{0}<0.25$, the SW peak increases in height as the accumulation potential becomes more positive. The effect of the accumulation potential in the real experiment could be understood through the influence upon the position of the equilibrium: $\mathrm{Hg} \Leftrightarrow \mathrm{Hg}^{2+}+2 \mathrm{e}^{-}$.

Since the mass transport of the reacting ligand is provided exclusively by the diffusion, the amount of the deposited salts and thus the peak currents depend linearly on the square root of the accumulation time. The peak potential and the half-peak width are independent on both the accumulation time and potential.

The effect of the adsorption upon the voltammetric response is represented by the adsorption parameter $\omega=$ $\frac{K_{\text {ads }} \sqrt{D}}{\sqrt{f}}$. This parameter reflects the influence of the adsorption strength of the reacting ligand through the adsorption constant $K_{\text {ads }}$. However the overall adsorption effect depends additionally on particular frequency $f$ of the SW signal and the diffusion coefficient of the ligand $D$.

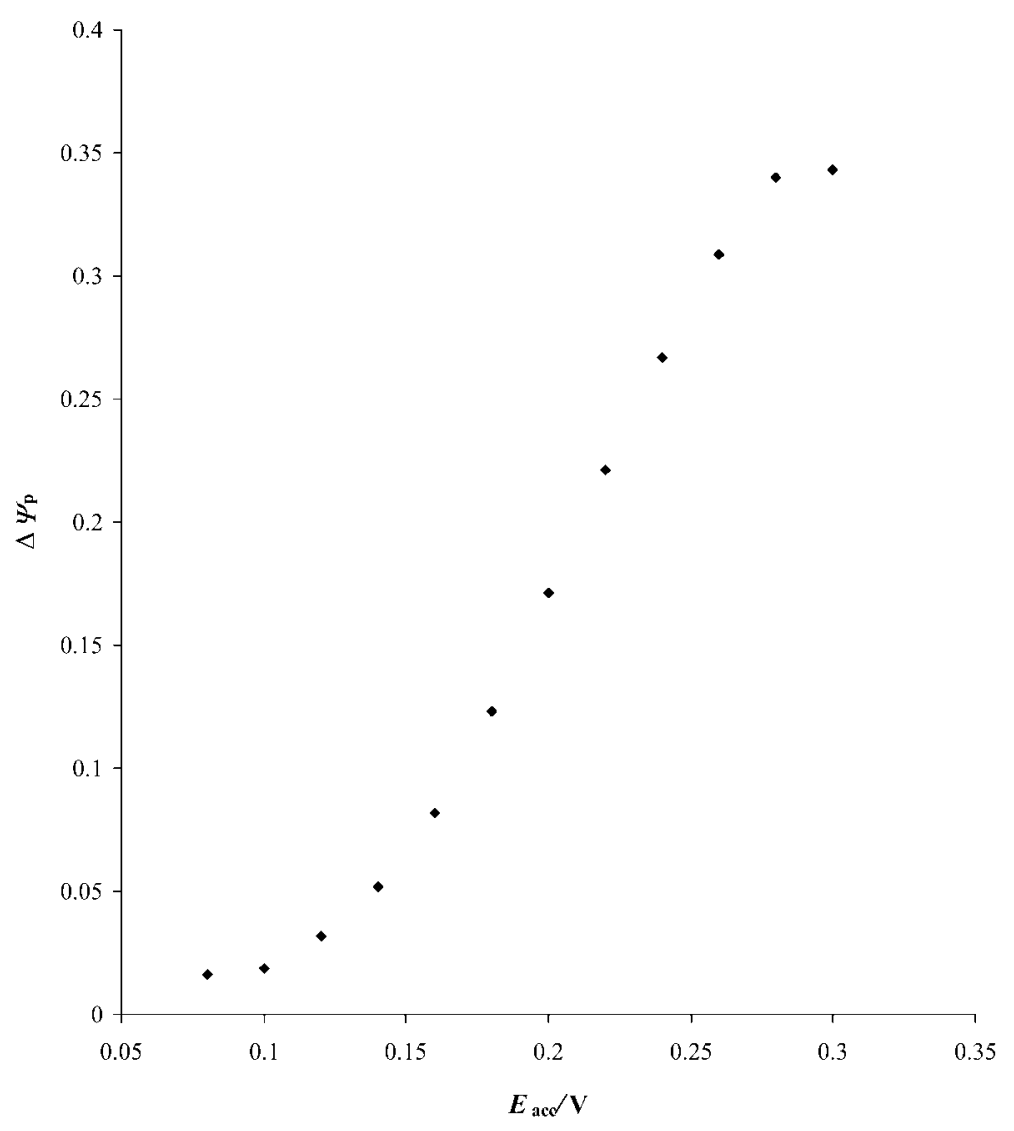

Fig. 1. Dependence of the dimensionless peak current $\Delta \Psi_{\mathrm{p}}$ on the accumulation potential $E_{\mathrm{acc}}$. The simulation conditions were: accumulation time $t_{\text {acc }}=1 \mathrm{~s}$, squarewave amplitude $E_{\mathrm{sw}}=25 \mathrm{mV}$, frequency $f=10 \mathrm{~Hz}$, potential step $\mathrm{d} E=10 \mathrm{mV}$, concentration of the ligand $c(\mathrm{~L})^{*}=5 \times 10^{-5} \mathrm{~mol} / \mathrm{cm}^{3}$, diffusion coefficient $D=5 \times$ $10^{-6} \mathrm{~cm}^{2} \mathrm{~s}^{-1}$, electron transfer coefficient $\alpha=0.5$, temperature $T=293 \mathrm{~K}$, and adsorption constant $K_{\text {ads }}=$ $50 \mathrm{~cm}^{-1}$.
The effect of the adsorption constant upon the peak current is illustrated in Figure 2 for three different ligand concentrations. The function $\Delta \Psi_{\mathrm{p}}-\log \left(K_{\mathrm{ads}}\right)$ is linear for each concentration of the ligand with a slope and intercept eing dependent on the particular ligand concentration. As be seen, enlarging the adsorption constant $K_{\text {ads }}$, which of view in particular. It means that the sensitivity of particular analytical method based on the studied redox mechanism will increase by decreasing the adsorption strength of the reaction ligand.

The peak potential also depends linearly on the logarithm of the adsorption constant (Fig. 3). The slope of the linear lines presented in Figure 3 is $\frac{\Delta E_{\mathrm{p}}}{\Delta \log \left(K_{\mathrm{ads}}\right)}=-2.303 \cdot \frac{R T}{2 F}$ regardless the concentration of the ligand.

The dependence of the dimensionless response on the concentration of the electroactive compound appears to be the most notable property of any electrode mechanism of second order. Figure 4 represents the dependence of the product $\Delta \Psi_{\mathrm{p}} \cdot c(\mathrm{~L})^{*}$ on $c(\mathrm{~L}) *$ for three different values of the
adsorption constant. Since the dimensionless peak current is defined as $\Delta \Psi_{\mathrm{p}}=\Delta I_{\mathrm{p}} /\left(2 F S c(\mathrm{~L})^{*}\right)(D f)^{1 / 2}$, the product $\Delta \Psi_{\mathrm{p}}$. $c(\mathrm{~L})^{*}$ corresponds to the real normalized peak current. Although the electrode mechanism is of a second order, the means decreasing the strength of the adsorption of the theoretical findings are important from an analytical point 


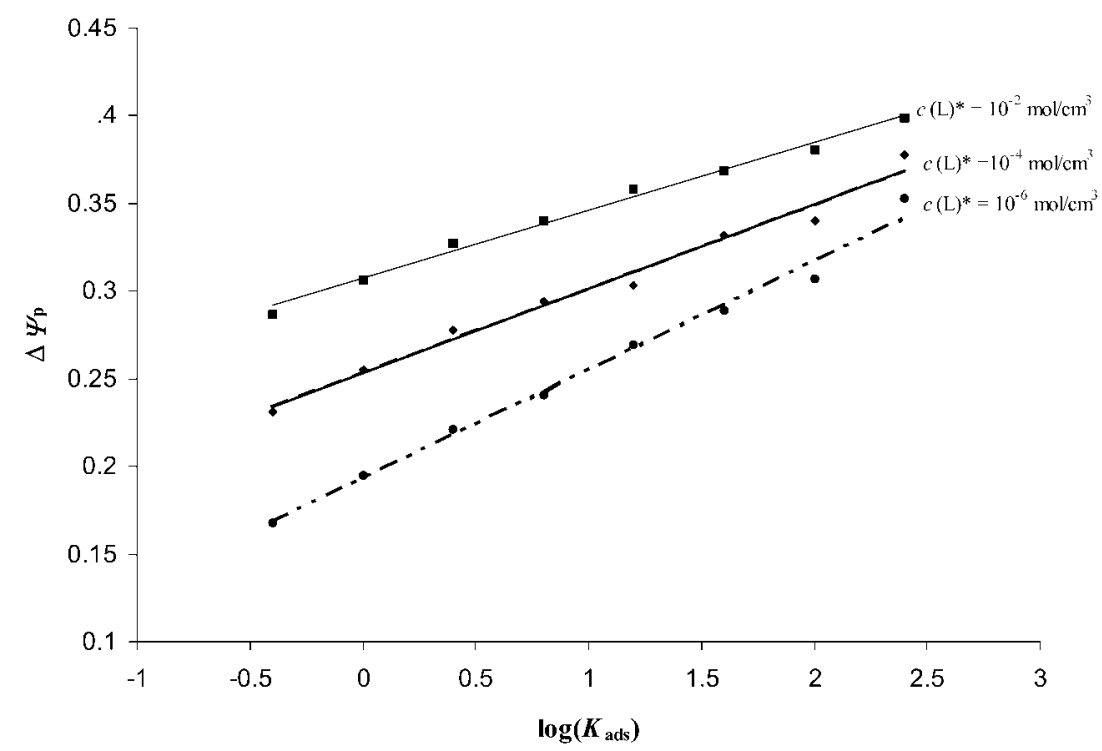

Fig. 2. Effect of the adsorption constant $K_{\text {ads }}$ on the dimensionless peak current for three different ligand concentrations. Accumulation potential $E_{\text {acc }}=0.15 \mathrm{~V}$. All other conditions of the simulation were the same as in the caption of Figure 1.

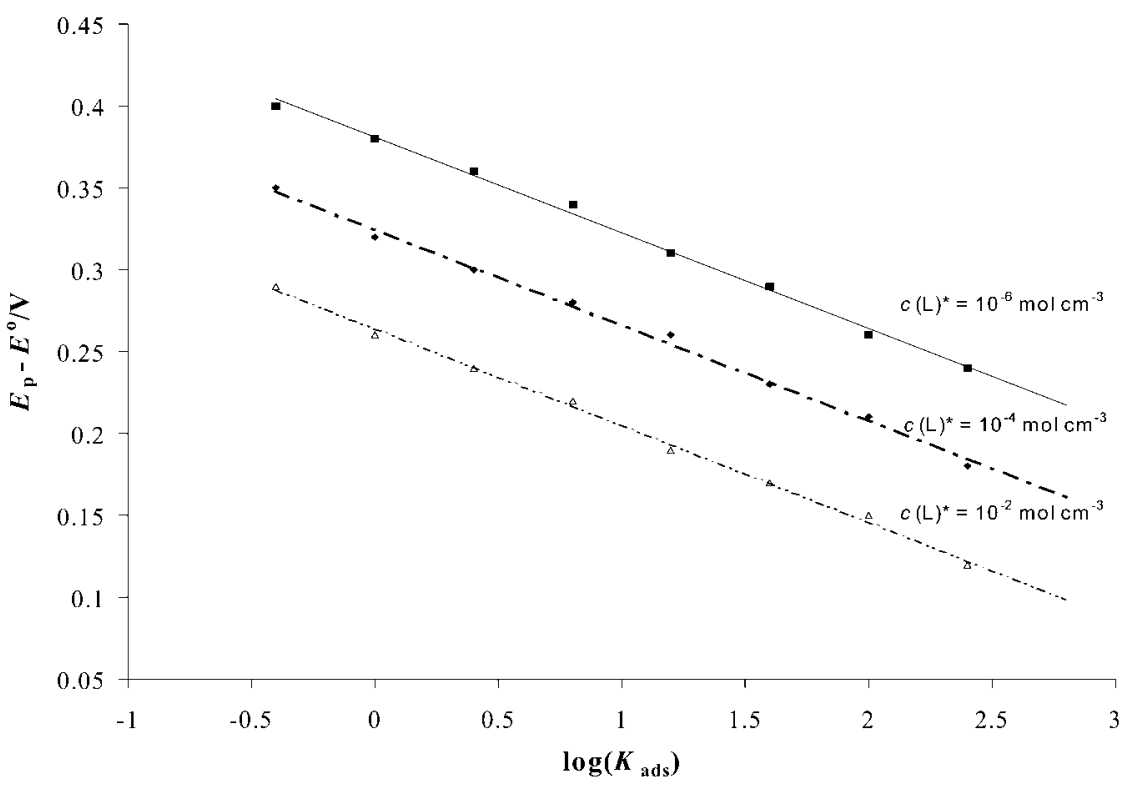

Fig. 3. Dependence of the peak potential $E_{\mathrm{p}}$ on the adsorption constant $K_{\text {ads }}$ for three different concentration of the ligand. The simulation conditions were the same as in Figure 1.

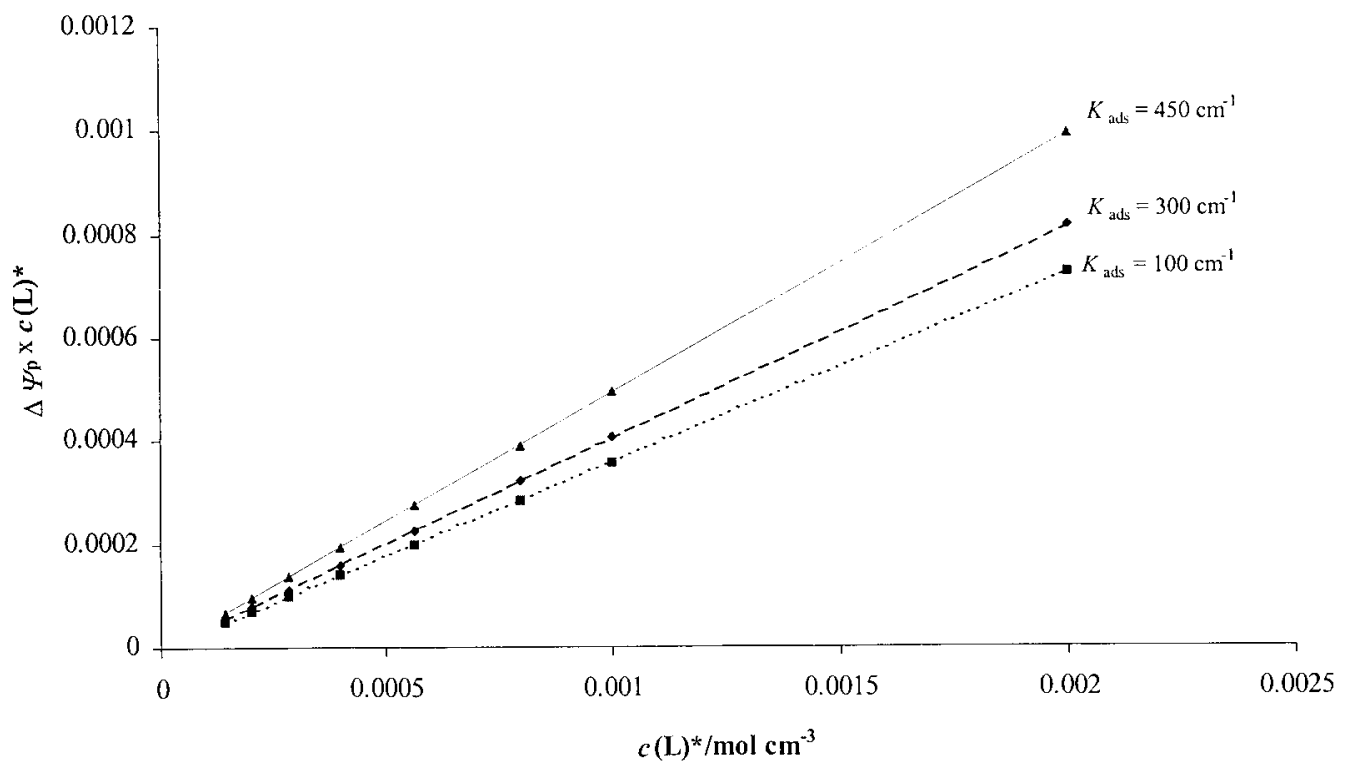

Fig. 4. Dependence of the product $\Delta \Psi_{\mathrm{p}} \times c(\mathrm{~L})^{*}$ on the ligand concentration for three different values of the adsorption constant. Accumulation potential $E_{\text {acc }}=$ $0.15 \mathrm{~V}$. For other conditions see the caption of Figure 1.

Electroanalysis 2002, 14, No. 5 
real peak current is still a linear function of the concentration of the ligand, which provides a basis for analytical application of this electrode mechanism. However, the slope of the relationship $\Delta I_{\mathrm{p}}-c(\mathrm{~L}) *$ depend on the adsorption constant of the ligand. Obviously, the weaker the adsorption strength of the reacting ligand the higher the sensitivity of the analytical method. These results are consistent with the previously derived conclusion regarding the effect of the adsorption upon the sensitivity of the analytical method.

The effect of the adsorption strength to the peak current appears as a result of the specific chronoamperometric properties of this electrode mechanism. In general, the current decreases exponentially in a course of a single potential pulse. The diminishing rate of the current depends on the adsorption strength of the reactant. The stronger the adsorption the more sever the decrease of the current. As a consequence, for strong adsorption of the reacting ligand, the less current amount remains to be measured at the end of the pulse. This could be regarded as a common behavior of all the processes occurring from an immobilized state of the reactant $[4,6,12-15]$.

In addition, the position of the response varies also with the ligand concentration, shifting the peak potential in negative direction by increasing the ligand concentration. The dependence $E_{\mathrm{p}}-\log \left(c(\mathrm{~L})^{*}\right)$ is linear with a constant slope of $\Delta E_{\mathrm{p}} / \Delta \log \left(c(\mathrm{~L})^{*}\right)=-2.303 R T /(2 F)$ and intercept being dependent on the adsorption constant (Fig. 5). This property of the peak potential should serve as a main criterion for distinguishing this mechanism from other first order cathodic stripping processes (Reaction I and III).

The height of the SW pulse (SW amplitude $E_{\mathrm{sw}}$ ) affects both the peak current and the half-peak width. The peak current enhances in proportion with the enhancement of the amplitude from 10 to $50 \mathrm{mV}$. For $E_{\mathrm{sw}}>50 \mathrm{mV}$, the peak current remains at a constant value. The shape of the SW voltammetric response is sensitive particularly to the signal amplitude. In general, the half-peak width increases with the signal amplitude. For instance, the half-peak width is 75 and $150 \mathrm{mV}$, for amplitude of 10 and $80 \mathrm{mV}$, respectively. For analytical purposes, the ratio $\Delta \Psi_{\mathrm{p}} / \Delta E_{\mathrm{p} / 2}$ is of particular interest. This quantity depends parabolically on the SW amplitude with a maximum positioned at about $E_{\mathrm{sw}}=$ $40 \mathrm{mV}$, indicating that this amplitude value is optimal for analytical measurements.

The frequency of the SW signal affects the peak current only. As expected, the normalized real peak current is linearly dependent on the frequency of the signal, which is a general property of all the redox mechanisms proceeding from an immobilized state of the reactant [12-17]. It is useful noting that for diffusion controlled redox reaction the real peak current depends linearly on the square root of the signal frequency [7].

At the end of this part, it seems beneficial to compare briefly the main properties of the studied reaction with the cathodic stripping process of second order without adsorption of the reacting ligand (Reaction II) [14]. Since both mechanisms are of second order, many similarities exist between them. The peak potential and the peak current depend on the ligand concentration in a similar manner for both mechanisms. However, in the case of redox mechanisms studied currently (Reaction IV), these dependencies are additionally complicated by the adsorption constant, which is not the case for Reaction II. Moreover, the peak potential of the studied reaction is insensitive to the signal frequency, whereas for Reaction II this dependence is linear with a constant slope of $\Delta E_{\mathrm{p}} / \Delta \log (f)=-2.303 R T /(4 F)$ [14].

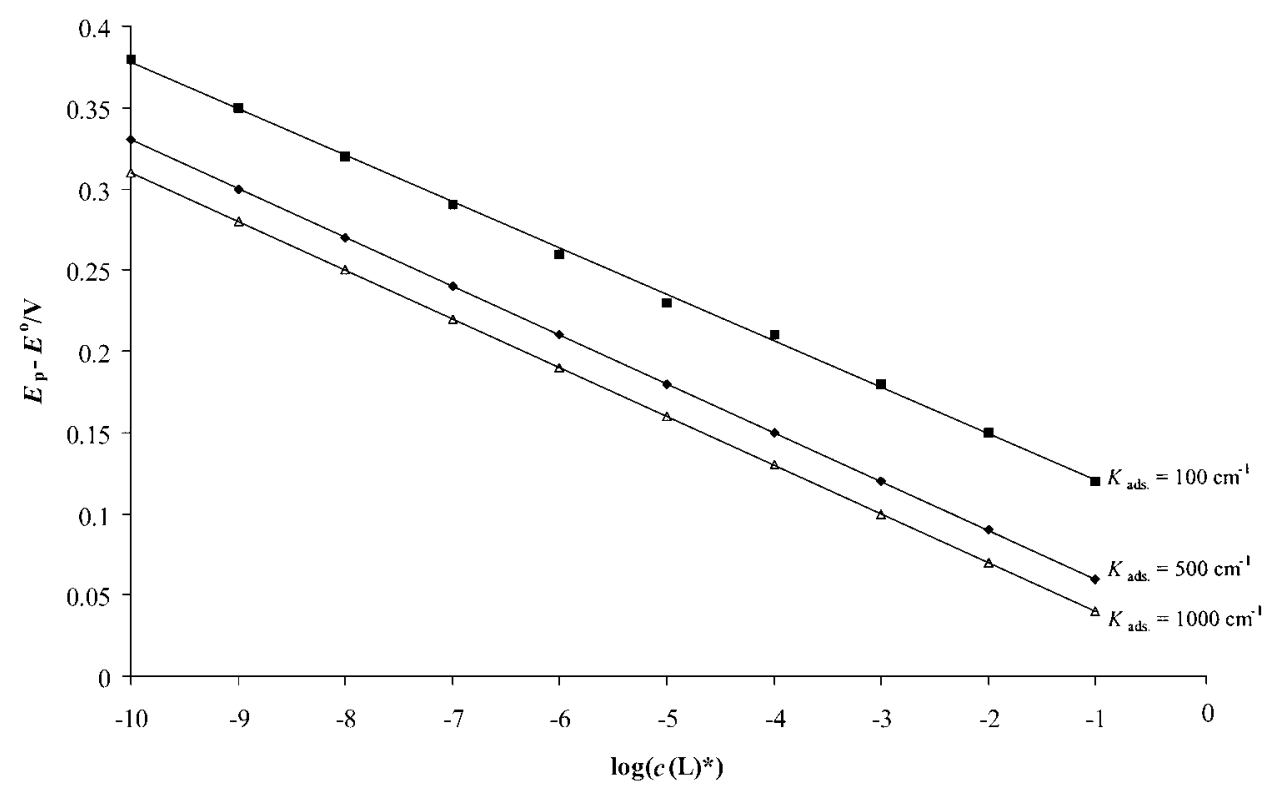

Fig. 5. Influence of the concentration of the ligand on the peak potential for three different values of the adsorption constant. For all other conditions see the caption of Figure 1. 


\subsection{Quasireversible Redox Reaction}

Besides the adsorption parameter $\omega=\frac{K_{\text {ads }} \sqrt{D}}{\sqrt{f}}$ and concentration of the ligand $c(\mathrm{~L}) *$ the voltammetric response of the quasireversible redox reaction is controlled additionally by a new kinetic parameter $K=k_{\mathrm{s}} /(D f)^{1 / 2}$ where $k_{\mathrm{s}}\left(\mathrm{cm} \mathrm{s}^{-1}\right)$ is standard rate constant and diffusion parameter $\gamma=\frac{\sqrt{D}}{r_{\mathrm{s}} \sqrt{f}}$. Kinetic parameter $K$ and diffusion parameter $\gamma$ represent the influence of charge transfer rate and diffusion of the reacting ligand, respectively. However, the apparent reversibility of the redox reaction is solely determined by a new complex kinetic argument $\chi$ defined as a product of the kinetic parameter $K$ and the adsorption parameter $\omega, \chi=$ $K \cdot \omega$. This crucial kinetic parameter can be defined as a function of the real parameters of the system $\chi=\frac{K_{\mathrm{ads}} k_{\mathrm{s}}}{f}$. Obviously, the diffusion parameter $\gamma$ does not contribute in the reversibility of the system. This sounds reasonably keeping in mind the fact that the entire redox reaction appears as a process of a completely confined redox couple.

The data in Table 1 confirm that the kinetic parameter $\chi$ determines the magnitude of the peak current with an average error of $4.2 \%$. The particular values of the parameter $\chi$ were adjusted by varying the standard rate constant for two different frequencies of the signal of $f=$ $10 \mathrm{~Hz}$ and $f=20 \mathrm{~Hz}$ and keeping all other parameters at a constant value.

The most intriguing property of the voltammetric response of the quasireversible redox reaction is a sharpparabolic dependence of the dimensionless peak current on the kinetic parameter $K$. Within the quasireversible region $(-1.5<\log (K)<1.5)$ the peak current increases dramatically reaching a maximum value for particular critical value of the kinetic argument $K_{\text {max }}$. This property is known as a "quasireversible maximum". The origin of this phenomenon is well understood from the theory of other cathodic stripping processes as well as the processes accompanied by adsorption of either the reactant or both the reactant and product of the redox reaction [4, 6, 12-17]. This is an exceptionally important property since it enables estimation of the standard rate constant by a simple and fast experimental procedure. The position of the quasireversible maximum of the currently studied redox reaction is a function of the adsorption constant, the concentration of the reacting ligand, the coefficient of the electron transfer and the height of the SW pulses.

As $K_{\text {ads }}$ increases, the position of the quasireversible maximum shifts towards less values of the kinetic argument $K$ (see Fig. 6). The interdependence between the critical values of the kinetic argument $K_{\max }$ and the adsorption constant $K_{\text {ads }}$ could be described as follows:

$\log \left(K_{\max }\right)=-0.0614 K_{\text {ads }} / \mathrm{cm}^{-1}+4.41$, which is valid for $\alpha=0.5$ and $E_{\mathrm{sw}}=25 \mathrm{mV}$. The latest equation enables the critical value of the kinetic argument to be determined if the adsorption constant of the reacting ligand is known.

In the real experiment, the quasireversible maximum could be reconstructed by varying the signal frequency over

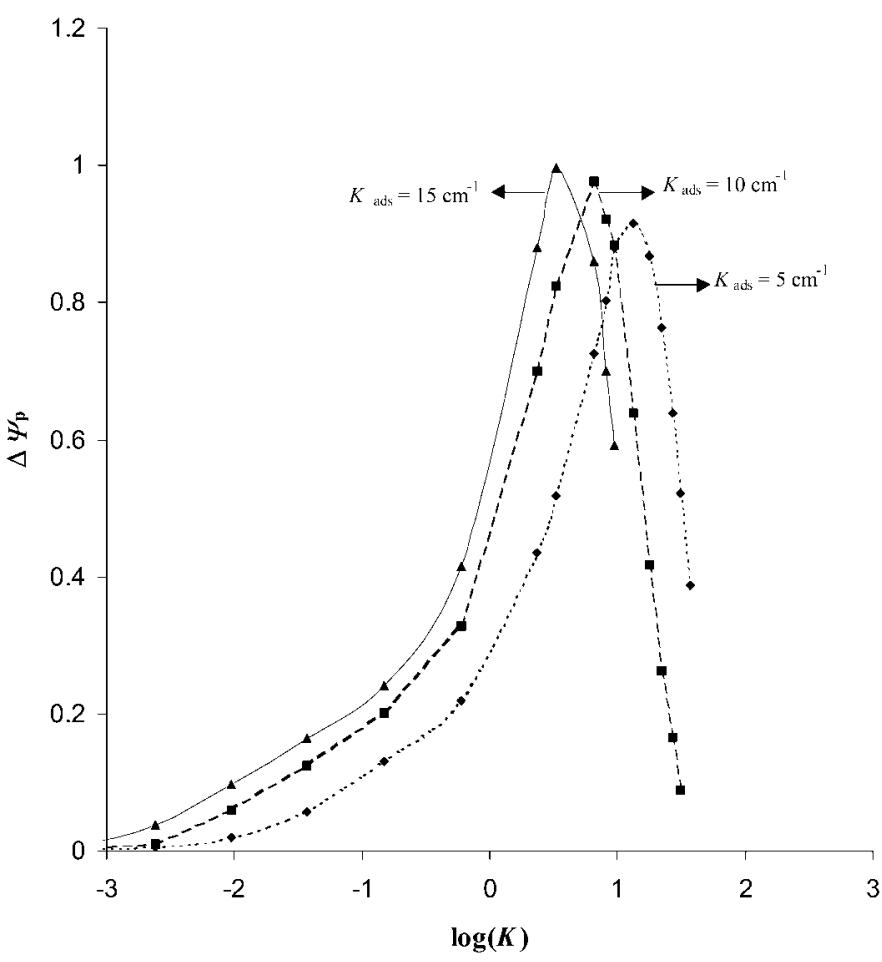

Fig. 6. Quasireversible reaction. Dependence of the dimensionless peak current $\Delta \Psi_{\mathrm{p}}$ on the logarithm of the kinetic parameter for three different values of the adsorption constant. The SW frequency $f=10 \mathrm{~Hz}, c(\mathrm{~L})^{*}=0.5 \mathrm{~mol} / \mathrm{cm}^{3}$ and accumulation potential $E_{\text {acc }}=0.15 \mathrm{~V}$. All the other conditions as in the caption of Figure 1.

Table 1. Comparison of the dimensionless peak currents and peak potentials as a function of the dimensionless parameter $\chi$ simulated for two different values of the SW frequency. The conditions for simulation are: SW amplitude $E_{\mathrm{sw}}=20 \mathrm{mV}$, potential increment $\mathrm{d} E=$ $10 \mathrm{mV}$, adsorption constant $K_{\text {ads }}=10 \mathrm{~cm}^{-1}$, accumulation time $t_{\mathrm{acc}}=1 \mathrm{~s}$ and accumulation potential $E_{\text {acc }}=0,15 \mathrm{~V}$.

\begin{tabular}{llllll}
\hline $\log (\chi)$ & $\Delta \Psi_{p}$ & $E_{p}(V)$ & $\Delta \Psi_{p}$ & $E_{p}(V)$ & Relative error \% \\
\cline { 2 - 6 } & $f=10 \mathrm{~Hz}$ & $f=10 \mathrm{~Hz}$ & $f=20 \mathrm{~Hz}$ & $f=20 \mathrm{~Hz}$ & \\
\hline 0.35 & 0.480 & -0.02 & 0.469 & -0.02 & 2.290 \\
0.60 & 0.602 & -0.01 & 0.573 & -0.01 & 4.817 \\
0.85 & 0.809 & 0 & 0.76 & 0.01 & 7.118 \\
1.10 & 1.152 & 0.01 & 1.07 & 0.02 & 5.000 \\
1.35 & 1.600 & 0.02 & 1.52 & 0.03 & 2.040 \\
1.60 & 1.960 & 0.03 & & & \\
\hline
\end{tabular}


the particular interval. Plotting the ratio $I_{\mathrm{p}} / f^{1 / 2}$, which corresponds to the dimensionless current, as a function of $\log \left(1 / f^{1 / 2}\right)$, which corresponds to the kinetic parameter $K$, one can reconstruct the theoretical analysis presented in the Fig. 6. If the critical signal frequency $f_{\max }$ associated with the quasireversible maximum is experimentally determined and the critical value of the kinetic argument $K_{\max }$ calculated theoretically, than the standard rate constant may be estimated through the simple relation $k_{\mathrm{s}}=K_{\max } \cdot f^{1 / 2}$ max . $D^{-1 / 2}$. Therefore, since this property enables estimation of the standard rate constant by a simple experimental procedure, it will be further analyzed theoretically.

The concentration of the reacting ligand affects the position of the quasireversible maximum if only $c(\mathrm{~L})^{*}>$ $0.1 \mathrm{~mol} / \mathrm{cm}^{3}$. The dependence of $K_{\max }$ on $c(\mathrm{~L})^{*}$ is described with the equation $\log \left(K_{\max }\right)=-0.506 c(\mathrm{~L}) * / \mathrm{mol} \mathrm{cm}^{-3}+$ 4.0112. This equation holds for $K_{\text {ads }}=10 \mathrm{~cm}^{-1}, \alpha=0.5$ and SW amplitude of $E_{\mathrm{sw}}=25 \mathrm{mV}$. In the real experiment, the concentration of the reacting ligand commonly ranges from $10^{-7} \mathrm{~mol} / \mathrm{cm}^{3}$ to $10^{-10} \mathrm{~mol} / \mathrm{cm}^{3}$. Thus, according to the above equation the concentration of the reacting ligand in the real experiment will exhibit insignificant influence on the position of the quasireversible maximum.

As mentioned previously, the position of the quasireversible maximum is also dependent on the electron transfer coefficient $\alpha$. This influence is illustrated with the following equation:

$\log \left(K_{\max }\right)=0.5017 \alpha+3.5352$. The latest equation was derived for $E_{\mathrm{sw}}=25 \mathrm{mV}$ and $K_{\mathrm{ads}}=10 \mathrm{~cm}^{-1}$. The scan increment exhibits no significant influence upon the position of the quasireversible maximum.

Besides the peak current, the kinetic argument $K$ also influences the position of the SW peak. Within the quasireversible region, the peak potential varies linearly with the logarithm of the kinetic parameter with a constant slope of $51 \mathrm{mV}$. It is important noting that the half-peak width is almost independent on the kinetic parameter $K$ over the large interval of $K$ values.

As in the case of the reversible redox reaction, although this mechanism is of second order, the peak current is still a linear function of the ligand concentration. The slope of the dependence $\Delta \Psi_{\mathrm{p}}-c(\mathrm{~L}) *$ increases as the adsorption strength of the ligand decreases, which is the same behavior as for the reversible redox reaction.

\subsection{Experimental Results}

6-Propyl-2-thiouracil (PTU) (see Fig. 7A), as a uracil derivative, is a cathodic stripping active compound $[4,18]$. Moreover, the detail study of the adsorptive behavior of PTU by both capacitive [19-21] and voltammetric [4, 15] measurements confirmed that PTU adsorbs strongly on the mercury electrode surface within the potential window where the reaction with mercury ions does not occur. Therefore, the general electrochemical behavior of PTU fulfils the main prerequisites for experimental illustration of the foregoing theoretical model.<smiles>CCCc1cc(O)nc(S)n1</smiles>

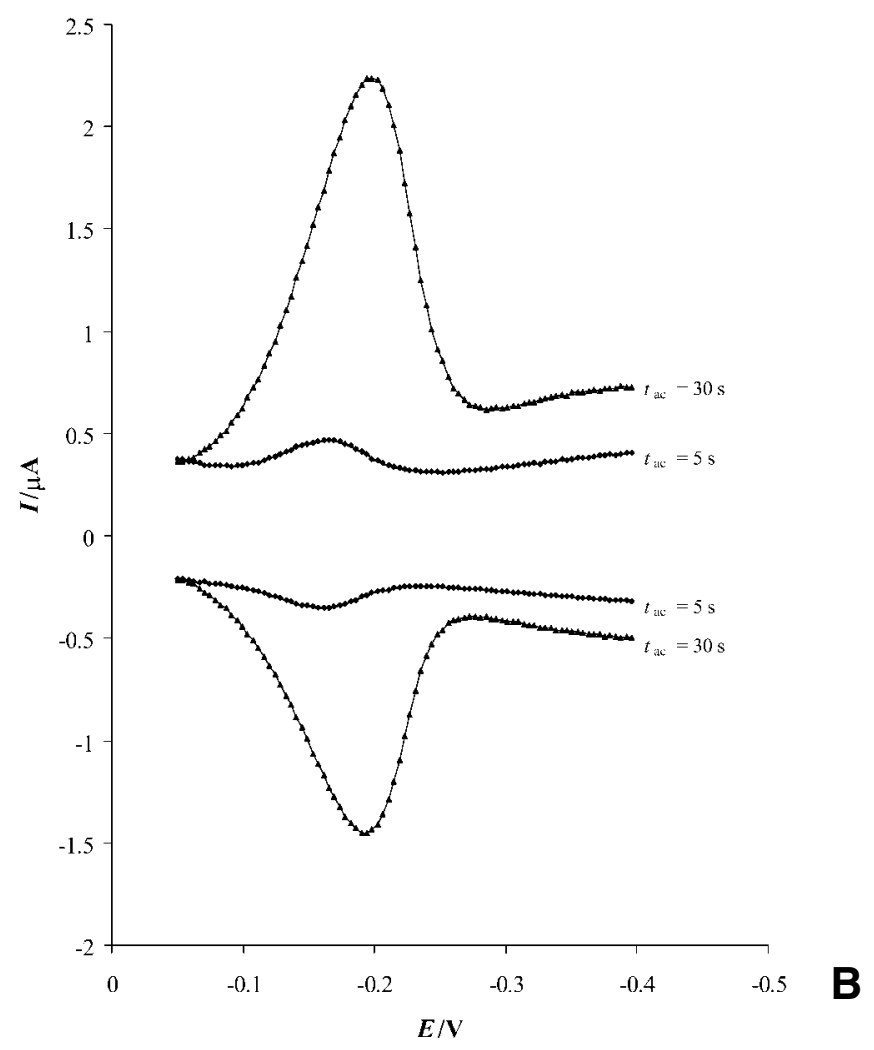

Fig. 7. A) Molecular structure of 6-propyl-2-thiouracil. B) Forward and backward components of the SW voltammetric response of $4 \times 10^{-6} \mathrm{~mol} / \mathrm{L}$ PTU solution recorded in $1 \mathrm{~mol} / \mathrm{L} \mathrm{KNO}_{3}$ solution for accumulation time of 5 and $30 \mathrm{~s}$. The other experimental conditions were: frequency $f=150 \mathrm{~Hz}$, amplitude $E_{\mathrm{sw}}=25 \mathrm{mV}$, scan increment $\mathrm{d} E=4 \mathrm{mV}$ and accumulation potential $E_{\text {acc }}=-0.1 \mathrm{~V}$.

The cathodic stripping voltammetric behavior of PTU at a hanging mercury drop electrode (HMDE) was studied in $1 \mathrm{~mol} / \mathrm{L} \mathrm{KNO}_{3}$. If the $\mathrm{HMDE}$ was polarized at potential of $E_{\text {acc }}=-0.1 \mathrm{~V}$ for a certain time, a sparingly soluble compound is formed between mercury and PTU molecules which remains deposited onto the electrode surface. In the course of the stripping step, this compound is dissolved from the electrode surface by a cathodic potential scan, yielding a well-defined cathodic stripping SWV peak with a peak potential of about $E_{\mathrm{p}}=-0.22 \mathrm{~V}$ and half-peak width of $\Delta E_{\mathrm{p} /}$ ${ }_{2}=50 \mathrm{mV}$.

Figure 7B shows the forward and backward component of the SWV response of $4 \times 10^{-6} \mathrm{~mol} / \mathrm{L}$ PTU solution recorded under increasing accumulation time. As the accumulation period increases, both component of the SWV response enhances in proportion to the duration of the deposition 
step. Moreover, in cyclic voltammetry, the subsequent cycling of the potential applied after certain accumulation period exhibits no significant influence to the cathodic and anodic CV peaks. Such a behavior is characteristic for the surface redox processes of an immobilized redox couple $[4,6]$.

The linear dependence of the peak potential on the logarithm of PTU concentration appears to be the most intriguing property of the SWV response of the mechanism studied. Figure 8 represents the $E_{\mathrm{p}}-\log (c(\mathrm{PTU}))$ relationship examined in the presence of various acetonitrile quantity in the supporting electrolyte. The acetonitrile was added in the supporting electrolyte with an idea to modify the adsorption strength of PTU. Since the acetonitrile could be itself adsorbed onto the electrode surface, it affects the adsorption constant of PTU by means of concurrent adsorption. However, it is particularly important to emphasize that the chemical activity of the PTU molecules is changed considerably in the presence of acetonitrile through the "salting-out" effect [23]. In the mixture wateracetonitrile the solubility of PTU increases considerably, which results in decreased ability for adsorption onto the working electrode surface.

For these reasons, the lines in the Figure 8 are characterized with a constant slope of about $-45 \mathrm{mV}$ and an intercept being dependent on the acetonitrile amount. These experimental results correspond to the theoretical analysis peak potential-ligand concentration performed under different adsorption strengths of the reacting ligand (see Fig. 5). The slope of the experimental lines in Figure 8 is less than that theoretically predicted for the reversible redox reaction, since the redox reaction of PTU is kinetically controlled under the selected experimental conditions.

The height of the SW peaks increases in proportion to the PTU concentration over the range from 1 to $9 \times 10^{-6} \mathrm{~mol} / \mathrm{L}$.
The slope of the $\Delta I_{\mathrm{p}}-c(\mathrm{PTU})$ function enhances by the increase of the acetonitrile amount, due to the lowering of the adsorption strength of PTU. These experimental findings are in excellent agreement with the theoretical results concerning the influence of the adsorption to the height of the voltammetric response (see Fig. 4).

In addition, the influence of acetonitrile upon the voltammetric response at a constant PTU concentration was examined. These experimental results correspond to the theoretical analysis in which the effect of the adsorption constant was studied. As the adsorption of PTU decreases by increasing the acetonitrile amount, the SW response shifts towards potentials that are more negative (see Fig. 9). The peak potential depends linearly on the logarithm of the volumic parts of ACN with a constant slope of $-27 \mathrm{mV}$ and an intercept that is determined by the distinctive concentration of PTU (see Fig. 9). At the same time, the SW peaks increase proportionally in height by decreasing the adsorption strength of PTU (see Fig. 10). Being in good agreement to the theoretical predictions, these results should be compared with the theoretical data presented in Figure 2 and Figure 3.

As mentioned previously, the quasireversible maximum is an inherent property of all cathodic stripping reactions $[4,6$, $12-17]$. In the real experiment, this phenomenon could be demonstrated by varying the signal frequency over a particular range of values. Figure 11 represents the quasireversible maximum of PTU constructed over the frequency interval from 40 to $500 \mathrm{~Hz}$. As can be seen from the figure, the abscise represents the ratio $1 / f^{1 / 2}$ which corresponds to the kinetic parameter $K=k_{\mathrm{s}} /(D f)^{1 / 2}$, whereas the ordinate represents the ratio $\Delta I_{\mathrm{p}} / f^{1 / 2}$ corresponding to the dimensionless current $\Delta \Psi_{\mathrm{p}}=\Delta I_{\mathrm{p}}\left(n F S c(\mathrm{~L})^{*}\right)^{-1}(D f)^{-1 / 2}$. The critical frequency at which the quasireversible maximum was

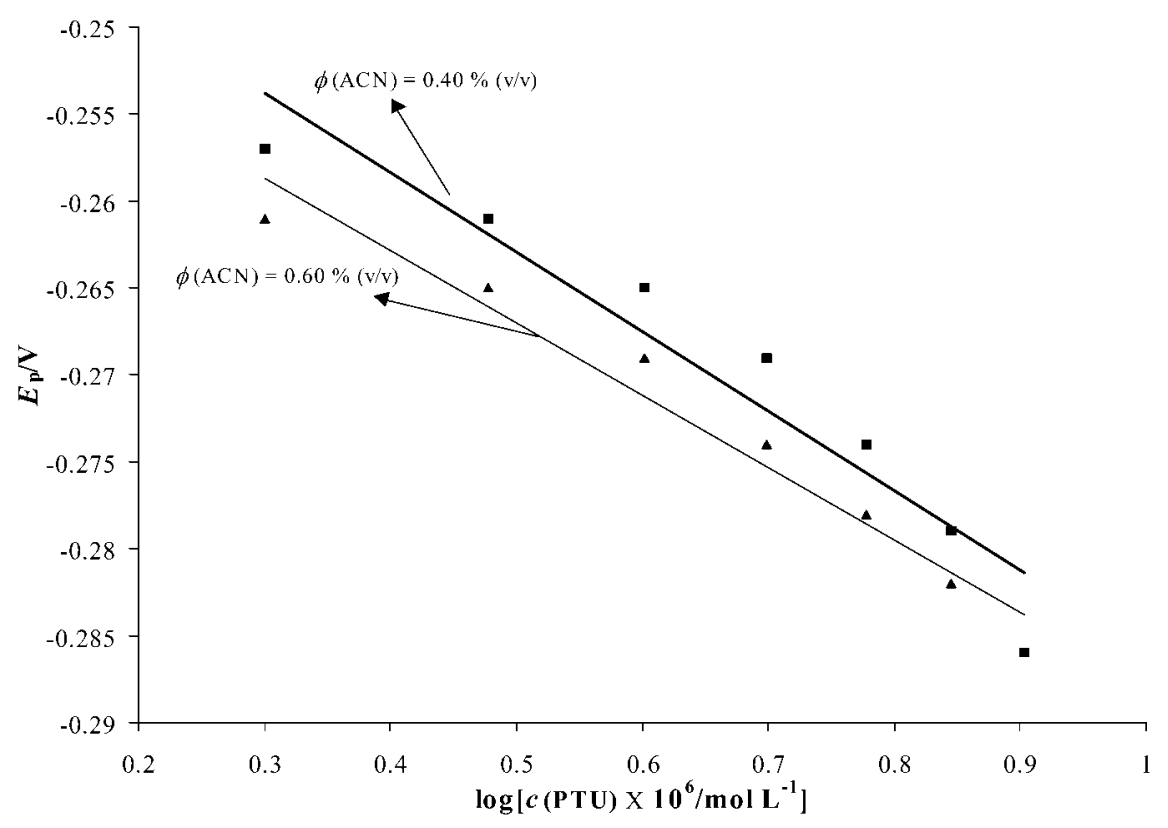

Fig. 8. Dependence of the SW peak potential on the PTU concentration recorded in $1 \mathrm{~mol} / \mathrm{L} \mathrm{KNO}_{3}$ solution containing $0.4 \%$ and $0.6 \%$ $(\mathrm{v} / \mathrm{v})$ acetonitrile. The accumulation time was $t_{\mathrm{acc}}=30 \mathrm{~s}$. Other conditions were the same as in the caption of Figure 7. 


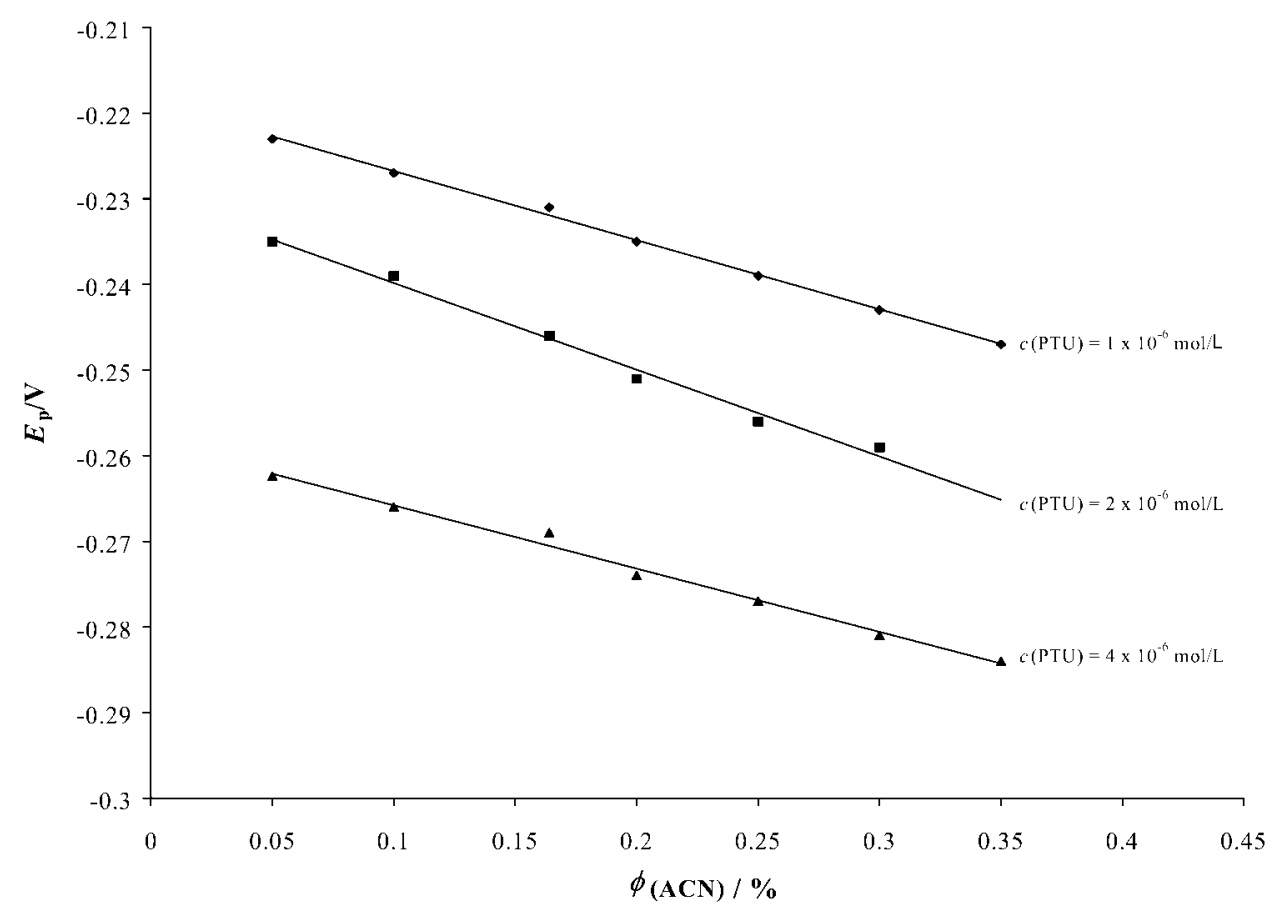

Fig. 9. Dependence of the SW peak potential on the volumic parts of acetronitrile, for three different concentration of PTU. The accumulation time was $t_{\text {acc }}=30 \mathrm{~s}$. For other conditions see the caption of Figure 7.

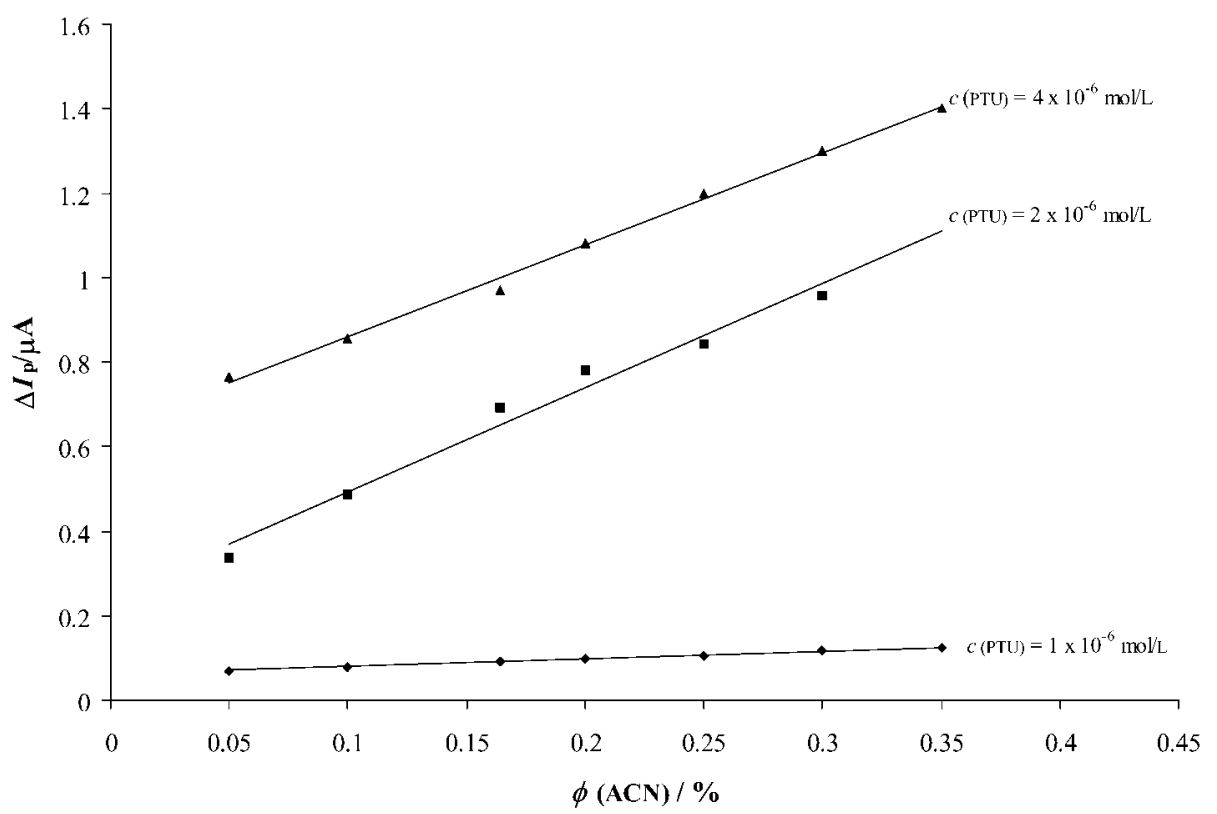

Fig. 10. Dependence of the peak current $\Delta I_{\mathrm{p}}$ on the volumic parts of acetonitrile, for three different concentration of PTU. The other experimental conditions were the same as in the caption of Figure 7.

attained, in the presence of $0.60 \%$ acetonitrile $(\mathrm{v} / \mathrm{v})$ is $f_{\max }=$ $100 \mathrm{~Hz}$. In addition, the quasireversible maximum was measured for three concentrations of PTU of $1 \times 10^{-6}, 5 \times$ $10^{-6}$, and $1 \times 10^{-5} \mathrm{~mol} / \mathrm{L}$. The critical frequencies were the same for each PTU concentration, as predicted by the theory.

All these results are in qualitative agreement to the theoretical results confirming the validity of the presented theory.

Electroanalysis 2002, 14, No. 5

\section{Acknowledgements}

Rubin Gulaboski thanks Deutscher Akademischer Austauschdienst (DAAD) for provision of a PhD Scholarship and Valentin Mirčeski thanks A. V. Humboldt for provision of a Humboldt fellowship. 


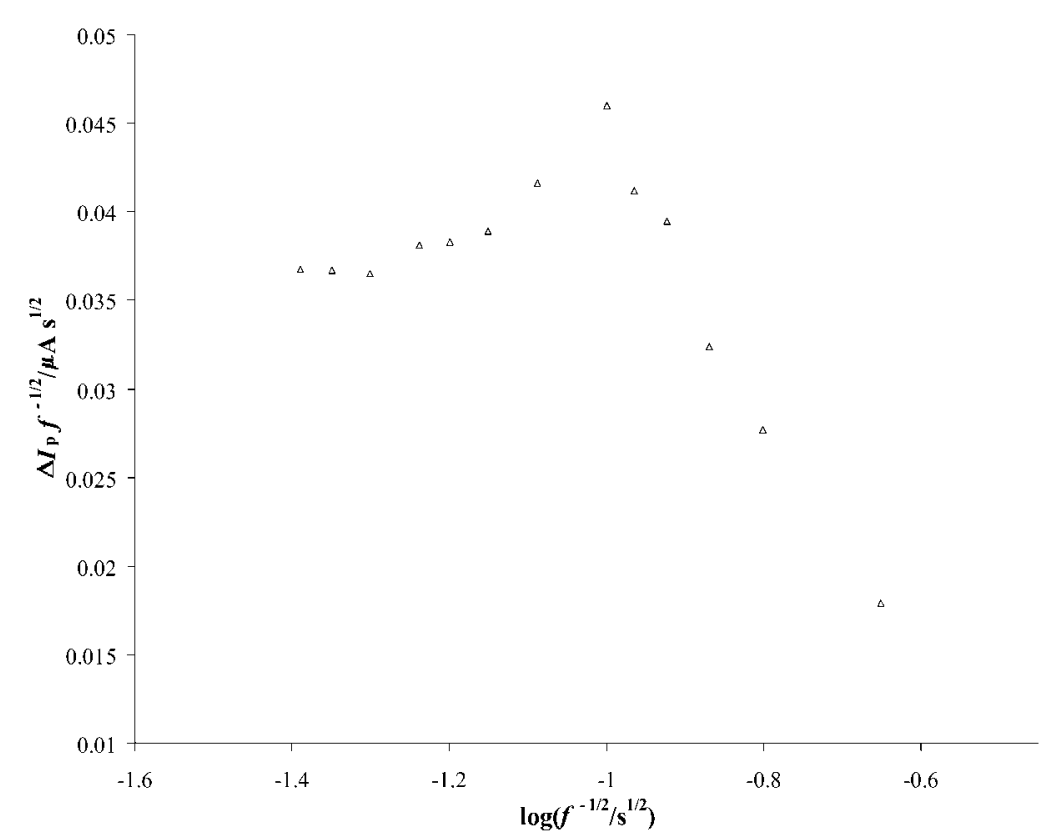

Fig. 11. Dependence of $\Delta I_{\mathrm{p}} / f^{1 / 2}$ on $1 / f^{1 / 2}$ in the presence of $0.6 \%(\mathrm{v} / \mathrm{v})$ acetonitrile. The accumulation time was $t_{\text {acc }}=30 \mathrm{~s}$. For other experimental conditions see the caption of Figure 7.

\section{Symbols and Abbreviations} $c(\mathrm{~L}) *\left(\mathrm{~mol} \mathrm{~cm}^{-3}\right)$
$c(\mathrm{~L})\left(\mathrm{mol} \mathrm{cm}^{-3}\right)$

$c(\mathrm{~L})_{x=0}\left(\mathrm{~mol} \mathrm{~cm}^{-3}\right)$

$D\left(\mathrm{~cm}^{2} \mathrm{~s}^{-1}\right)$

$E(\mathrm{~V})$

$E_{\mathrm{sw}}(\mathrm{mV})$

$\mathrm{d} E(\mathrm{mV})$

$E_{\mathrm{p}}(\mathrm{V})$

$F\left(\mathrm{~A} \mathrm{~s} \mathrm{~mol}^{-1}\right)$

$f\left(\mathrm{~s}^{-1}\right)$

I(A)

$\Delta I_{\mathrm{p}}(\mathrm{A})$

$k_{\mathrm{s}}\left(\mathrm{cm} \mathrm{s}^{-1}\right)$

$K_{\text {ads }}\left(\mathrm{cm}^{-1}\right)$

$R\left(\mathrm{~J} \mathrm{~mol}^{-1} \mathrm{~K}^{-1}\right)$

$S\left(\mathrm{~cm}^{2}\right)$

$T(\mathrm{~K})$

$t(\mathrm{~s})$

$\alpha$

$\Gamma\left(\mathrm{HgL}_{2}\right)\left(\mathrm{mol} \mathrm{cm}^{-2}\right)$

$\Gamma(\mathrm{L})\left(\mathrm{mol} \mathrm{cm}^{-2}\right)$

$\Psi$

$\Delta \Psi_{\mathrm{p}}$

\section{References}

[1] Kh. Z. Brainina, Talanta 1971, 18, 513.

[2] J. Wang, Stripping Analysis, VCH Publishers, Deerfield Beach, 1985. bulk concentration of the ligand ions concentration of the ligand ions anywhere in solution

concentrations of the $\mathrm{L}^{-}$at the electrode surface

diffusion coefficient

potential of the working electrode

SWV pulse height

SWV scan increment

Faraday constant

frequency

current

SWV peak current

standard rate constant

adsorption constant

gas constant

electrode surface area

temperature

time

electron transfer coefficient

surface concentration of the insoluble

salt $\mathrm{HgL}_{2}(\mathrm{~s})$

surface concentration of the adsorbed ligand $\mathrm{L}^{-}$

dimensionless current

dimensionless peak current peak potential
[3] T. M. Florence, J. Electroanal. Chem. 1979, 97, 219 and 237.

[4] V. Mirčeski, M. Lovrić, Anal. Chim. Acta 1999, 386, 47.

[5] M. Khodari, M. Ghandour, A. M. Taha, Talanta 1997, 44, 305.

[6] V. Mirčeski, R. Gulaboski, B. Jordanoski, Ŝ. KomorskyLovrić, J. Electroanal. Chem. 2000, 490, 37.

[7] J. G. Osteryoung, R. A. Osteryoung, Anal. Chem. 1985, 57, $101 \mathrm{~A}$.

[8] J. J. O'Dea, J. G. Osteryoung, R. A. Osteryoung, Anal. Chem. 1981, 53, 695.

[9] J. J. O’Dea, J. G. Osteryoung, R. A. Osteryoung, J. Phys. Chem. 1983, 87, 3911.

[10] S. P. Kounaves, J. J. O'Dea, P. Chadrasekhar, J. G. Osteryoung, Anal. Chem. 1986, 58, 3199.

[11] E. Zachowski, M. Wojciechowski, J. G. Osteryoung, Anal. Chim. Acta 1986, 183, 477 .

[12] M. Lovrić, I. Pizeta, S. Komorsky-Lovrić, Electroanalysis $1992,4,327$.

[13] V. Mirčeski, M. Lovrić, Electroanalysis 1999, 11, 984.

[14] V. Mirčeski, M. Lovrić, Electroanalysis 1998, 10, 976.

[15] V. Mirčeski, B. Jordanoski, M. Avramov-Ivić, J. Serb. Chem. Soc. 1998, 63, 719.

[16] M. Lovrić, Ŝ. Komorsky-Lovrić, J. Electroanal. Chem. 1988, $248,239$.

[17] $\hat{S}$. Komorsky-Lovrić, M. Lovrić, M. Branica, J. Electroanal. Chem. 1992, 335, 297.

[18] B. Bouzid, A. Macdonald, Anal. Chim. Acta 1988, 221, 155.

[19] T. Wandlowski, E. Kretchmer, E. Mueller, F. Kuschel, F. Hoffmann, K. von Lipinski, J. Electroanal. Chem. 1986, 213, 339.

[20] T. Wandlowski, J. Electroanal. Chem. 1991, 312, 245.

[21] T. Wandlowski, R. de Levie, J. Electroanal. Chem. 1991, 312, 245.

[22] R. S. Nicholson, M. L. Olmstead, in Electrochemistry: Calculations, Simulation and Instrumentation, Vol. 2 (J. S. Mattson, H. B. Mark, H. C. MacDonald), Marcel Dekker, New York 1972.

[23] N. B. Grigorev, B. B. Damaskin, Advances in Electrochemistry of Organic Compounds, Izd. Nauka, Moscow 1968. 